\title{
Da teoria à prática: problematização e metodologias diferenciadas no Cálculo Numérico
}

\author{
Carmem Lucia Graboski Gama ${ }^{1}$ \\ Mateus das Neves Gomes ${ }^{2}$ \\ Liceia Alves Pires ${ }^{3}$
}

\section{RESUMO}

Esse trabalho apresenta um estudo de caso que aborda a disciplina de Cálculo Numérico, em um curso de Licenciatura em Matemática em uma Universidade Estadual do Paraná,com metodologias diferenciadas, empregando a resolução de problemas, a modelagem matemática e as novas tecnologias como forma de minimizar os problemas de aprendizagem. Para isso, foi realizada com a referida turma uma atividade prática, em que os alunos deveriam encontrar resposta a um problema real, usando as metodologias empregadas no decorrer do curso e também os conceitos vistos em Cálculo Numérico. Após essa atividade os alunos fizeram uma avaliação que buscou identificar se a forma de trabalho os axiliou na aprendizagem. Pelas respostas percebeu-se que a grande maioria das respostas foram positivas, ou seja, os alunos aprenderam de forma diferenciada. Quando questionados se o dia que atuarem como professor, lecionariam usando as metodologias vivenciadas, todos responderam que sim. Com o trabalho, pode-se perceber que é possível e interessante que as aulas de Cálculo Numérico não fiquem somente restritas aos métodos tradicionais, mas que estas possam estar articulados com outras metodologias mais ativas.

PALAVRAS-CHAVE: Cálculo Numérico. Metodologias diferenciadas. Licenciatura em Matemática

From theory to practice: problematization and differentiated methodologies in Numerical Calculus

\footnotetext{
${ }^{1}$ Doutora em Métodos Numéricos em Engenharia. Instituto Federal do Paraná - Campus Paranaguá, Paranaguá, Brasil. E-mail: carmem.gama@ifpr.edu.br

${ }^{2}$ Doutor em Engenharia Mecânica. Instituto Federal do Paraná - Campus Paranaguá, Paranaguá, Brasil. E-mail: mateus.gomes@ifpr.edu.br

${ }^{3}$ Doutoranda do Programa de Pós-Graduação em Educação da PUC-PR. E-mail: liceia.pires@unespar.edu.br
} 


\begin{abstract}
This paper presents a case study performed with Numerical Calculus class, in the Mathematical undergraduate of University State Paraná. Differentiated methodologies were employed through problem solving, mathematical modeling and new technologies. The goal was to minimize learning problems. For this, a practical activity was carried out with the said class, in which the students had to find an answer to a real problem, using the methodologies used during the course and also the concepts seen in Numerical Calculus. After this activity, it was necessary to maked an evaluation that sought to identified a form of worked in the school.From the answers it was noticed that a great majority of the answers were positive, that is, the students learned in a different way. When asked if the day they act as teacher, would teach using the methodologies experienced, everyone answered yes. With this work, one can see that it is possible and interesting that Numerical Calculus classes are not only restricted to traditional methods, but that these can be articulated with other methodologies that are more active
\end{abstract}

KEYWORDS: Numerical Calculus. Differente methodologies. Degreen in mathematics.

$$
* * *
$$

\title{
Introdução
}

Muitas vezes ao lecionar a disciplina de cálculo numérico, nos cursos de graduação, o professor percebe que os acadêmicos não conseguem entender a sua aplicabilidade em situações reais e, dessa forma, muitas vezes se sentem desmotivados.

Um fator que pode contribuir para essa situação é a metodologia empregada na disciplina, o que muitas vezes se caracteriza apenas como tradicional, e entende-se, nesse estudo, como método tradicional aquele que o professor apresenta a teoria, exemplos e os alunos resolvem exercícios e realizam avaliações (provas individuais), como forma de verificação da aprendizagem. 
Buscando uma perspectiva metodológica diferenciada para o ensino do cálculo numérico, este trabalho apresenta, em forma de um estudo de caso, como é possível desenvolver algumas atividades diferenciadas, que tragam problemas reais a serem resolvidos nas aulas.

Essas metodologias: Resolução de Problemas, Modelagem Matemática e Novas Tecnologias, que trazem o problema real para a sala de aula, a ser resolvido com diferentes métodos, foram aplicadas em um curso de Licenciatura em Matemática no Município de Paranaguá no Estado do Paraná, numa Universidade Estadual, com alunos formandos de matemática, no ano de 2015 e 2016.

\section{A modelagem matemática}

A modelagem matemática pode ser vista como um conjunto de procedimentos que buscam fazer uma descrição matemática de um determinado fenômeno que está presente no mundo real. Ao longo dos anos o homem sempre utilizou modelos para resolver situações problema com as quais se deparava. Nesse sentido,

A Modelagem Matemática é um processo dinâmico utilizado para a obtenção e validação de modelos matemáticos. É uma forma de abstração e generalização com a finalidade de previsão de tendências. A modelagem consiste, essencialmente, na arte de transformar situações da realidade em problemas matemáticos cujas soluções devem ser interpretadas na linguagem usual. (BASSANEZI, 2002, p. 24)

Por meio da modelagem matemática, alguns problemas de diferentes áreas do conhecimento podem ser resolvidos, problemas estes que podem envolver o estudo de fenômenos ligados à saúde, ao meio ambiente, à administração, à teoria de decisão, dentre outros. 
$\mathrm{Na}$ educação, nos últimos anos, a modelagem matemática também está presente. Para Almeida (2013, p.12) “(...) a “origem” da Modelagem Matemática não se deu no âmbito da Educação Matemática. Pelo contrário o habitat natural da Modelagem Matemática é a área que se convencionou chamar de Matemática Aplicada.”, pois foi nesse meio, de aplicação da matemática, que surgiram os primeiros conceitos de modelagem e, posteriormente, a aplicação dos mesmos na Educação Matemática sob diferentes abordagens.

Atualmente, a modelagem matemática pode ser estudada como uma metodologia de ensino na educação básica ou até mesmo como uma disciplina no curso de matemática com o objetivo de auxiliar os alunos na aprendizagem da matemática.

\section{Resolução de problemas como metodologia de ensino}

Como metodologia de ensino, a resolução de problemas é uma das maneiras de levar o aluno a ter a oportunidade de aplicar conhecimentos matemáticos que aprendeu em sala de aula para resolver problemas novos, com novas abordagens e assim torna-lo mais habilitado para trabalhar com a matemática, seus conceitos e aplicações. Dante (1989,p.15), alerta os educadores que:

(...) é necessário formar cidadãos matematicamente alfabetizados, que saibam como resolver, de modo inteligente, seus problemas de comércio, economia, administração, engenharia, medicina e previsão do tempo e de outros da vida diária. (DANTE, 1989, p.15)

Ensinar a resolver problemas, da forma como é feita hoje, teve inicio com Polya em 1960, nos Estados Unidos, para Colombo (2005, p.16) "Entretanto, há referências de outro pesquisador e outras datas tais como Dewey (1896 e 1904) e Polya (1945) que já haviam realizados algumas 
experiências significativas (...)", tais experiências ainda não se configuravam com uma metodologia de ensino.

É importante lembrar que ensinar por meio de problemas ajuda os alunos a perceberem a importância da disciplina que está cursando, pois ajuda a visualizar onde a mesma pode ser inserida, quando se busca solucionar problemas que aparecem no dia a dia.

Para explanar sobre alguns tipos de problemas e suas etapas de resolução, que podem ser aplicados em sala de aula, neste trabalho foi utilizado como autor base Polya (2006, p.04-15). O autor apresenta que um problema pode ser resolvido mediante o emprego de quatro fases: a primeira é a compreensão do problema; a segunda se refere ao estabelecimento de um plano; a terceira onde ocorre a execução do plano e a última, onde é realizado o retrospecto.

\section{Tecnologias na educação}

Por mais que exista resistência por parte de professores e educadores em trazer as novas tecnologias para dentro da sala de aula, é algo que já estão sendo considerada como uma metodologia de ensino.

No entanto, é preciso estar atento que utilizar as novas tecnologias em sala de aula não é apenas levar os alunos a um laboratório faz-se necessário criar um ambiente “(..) onde cada grupo utilize os equipamentos necessários, de acordo com as suas necessidades. O problema não é saber ou não utilizar os computadores, é a informação." (OLIVEIRA, MARIM, 2010, p. 180). Essa ideia é complementada por Brasil (2008, p. 89) que apresenta "No uso de tecnologias para o aprendizado da Matemática, a escolha de um programa torna-se um fator que determina a qualidade do aprendizado".

Um recurso tecnológico de grande importância na matemática é o software GeoGebra, “(..) que reúne geometria, álgebra e cálculo." (Hohenwarter, 2007), o qual foi desenvolvido por Markus Hohenwarter para a educação matemática nas escolas. 
$\mathrm{Na}$ área de Cálculo Numérico pode-se utilizar o Visual Cálculo Numérico (VCN) que é software educacional criado pelos professores da PUC de Minas, para auxiliar os alunos do ensino superior na área de ciências exatas, especialmente para a disciplina de Cálculo Numérico e também auxilia na resolução de problemas do Cálculo Diferencial de Integral.

Por meio do VCN, o aluno pode obter solução para problemas que envolvam raízes de funções ou zero de equações, erros e representações numéricas, interpolação e extrapolação numérica, sistemas lineares e não lineares, ajuste de curvas, otimização, dentre outras.

\section{Cálculo Numérico}

Como disciplina, o cálculo numérico pode estar inserido nos cursos de graduação de Licenciatura e Bacharelado em matemática, nas engenharias e nos cursos de economia, isso porque, as ferramentas do cálculo numérico buscam a solução de problemas que o cálculo analítico, muitas vezes, não consegue solucionar ou que são de difícil resolução.

Para Amaral et al (2013,p.1), "Entre os objetivos do estudo do Cálculo Numérico, podemos destacar o estudo dos métodos numéricos para resolução de problemas em geral tais como de engenharia, economia, ambientais, biológicos entre outros.”, ou seja, por meio do cálculo numérico encontram-se soluções aproximadas de problemas complexos.

Para Sperandio (2003, p. 2), "o cálculo numérico tem sua importância centrada no fato de que, mesmo quando a solução analítica é difícil de ser obtida, as técnicas numéricas podem ser empregadas sem maiores dificuldades", enquanto ciência, surge a partir do Século XVIII, não desvinculado do cálculo analítico.

Não existe uma precisão de datas, separando os trabalhos de cálculo analítico do cálculo numérico. Até essa época problemas eram resolvidos sem que se pensasse na possibilidade de soluções numéricas de forma 
isolada. Foi com Newton (1642-1727), Lagrange (1736-1813), Gauss (17771855), Raphson (1648-1715) entre outros, que o cálculo numérico ganha destaque.

Segundo Eves (2004, p.450), "Newton descobriu um método para aproximar os valores das raízes reais de uma equação numérica, aplicável tanto para equações algébricas como para equações transcendentes”.

Já para encontrar solução de sistemas de equação, é importante destacar os métodos iterativos de Gauss Seidel ou de Gauss Jacobi, que buscam solução para um sistema de equações lineares.

Nessa época, as soluções de equações, de sistemas de equação, interpolações entre outros temas eram estudados apenas com o objetivo de estudar a matemática ou aplicá-la a problemas da física e da astronomia. Entre o século XVIII e XIX, surgem muitos trabalhos na área que vem a dar um destaque especial ao cálculo numérico.

Como disciplina, ele surge no Brasil a partir de escolas de engenharia em São Paulo e Rio de Janeiro. Para Noguti (2005, p.6):

O Cálculo Numérico aparece como disciplina nos cursos de engenharia e, em meados da década de 50, os professores da disciplina eram, em sua grande maioria, engenheiros. Nas décadas posteriores, com o advento dos computadores e a divisão da matemática em pura e aplicada, criaram-se novos departamentos de matemática aplicada e, com eles, as disciplinas de cálculo numérico para os cursos de matemática.

Como existem na literatura poucos trabalhos que tratem do ensino e aprendizagem do cálculo numérico é que, nesse trabalho, se busca apresentar como o professor pode usar nas aulas algumas metodologias alternativas tais como: modelagem, resolução de problemas e tecnologias, como forma diferenciada de lecionar a disciplina. 


\section{O contexto do trabalho com as diferentes metodologias}

Esse trabalho foi realizado em um quarto ano de um curso de Licenciatura em Matemática, de uma Universidade Estadual do Estado do Paraná, no terceiro bimestre, que devido a greve estadual, ficou situado entre os meses de novembro e dezembro de 2015 e teve continuidade em fevereiro de 2016.

A referida turma é composta de 9 alunos, oriundos de um ensino médio da rede pública estadual, trabalhadores, que atuam na rede privada, na área de saúde, administração, portuária e como professores contratados.

Durante o primeiro e segundo bimestre de 2015, os alunos tiveram as aulas de cálculo de forma tradicional, ou seja, eram apresentadas as teorias e os alunos tentavam resolver os exercícios e atividades propostas. No início do terceiro bimestre foi proposto o trabalho de forma diferenciada, usando a resolução de problemas, a modelagem e as novas tecnologias como metodologias de ensino para a disciplina.

No primeiro encontro, foi apresentado um problema, onde deveriam encontrar a área territorial de uma determinada Ilha no Estado do Paraná. A turma foi dividida em três grupos A, B e C com três alunos cada. O problema proposto era encontrar a área territorial da Ilha do Mel, na Cidade de Paranaguá, Estado do Paraná, tendo como base a (Fig. 1) abaixo:

FIGURA 1: Mapa da Ilha do Mel

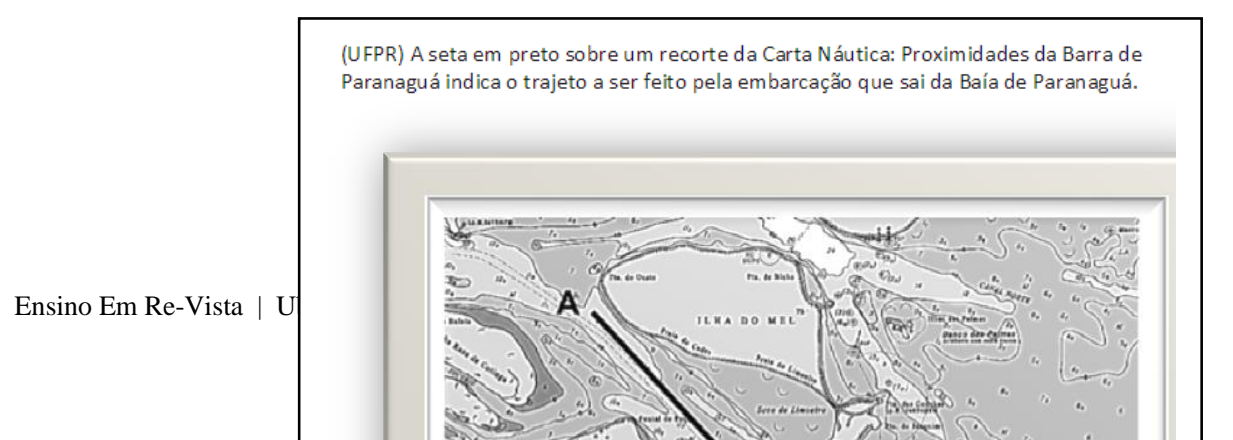


A Ilha do Mel, segundo dados da Prefeitura Municipal de Paranaguá (2016), está situada no Município de Paranaguá, estado do Paraná e conta com aproximadamente $95 \%$ de sua área territorial composta por ecossistemas de restinga e Floresta Atlântica. Tem 2.700 ha, sendo destes apenas 200 ha com permissão para uso.

Após esse primeiro contato com o problema, foram disponibilizadas 4 horas aula para que os alunos em grupo A, B e C buscassem resolver o problema ou criassem estratégias de como iniciar a sua solução. Somente um grupo conseguiu esboçar um rascunho para a solução do problema, que primeiro foi feito em um papel e depois os dados foram transpostos para $o$ geogebra.

O trabalho consistiu em tentar encontrar as áreas de pequenos triângulos usando o software, porém pelas respostas encontradas perceberam que esse não poderia ser o caminho. Conforme a (Fig 2.) abaixo.

FIGURA 2: Esboço da solução inicial pela equipe B 
A ideia inicial do grupo B era traçar triângulos na figura que formava a área territorial da Ilha do Mel e tentar encontrar uma área aproximada, usando uma regra de três e buscando um polinômio linear que descrevesse pequenos contornos da figura. Após algumas discussões e questionamentos perceberam que essa não era uma boa saída para o problema e ficaram de pensar em algo melhor. Os grupos A e C não apresentaram nenhum esboço de solução, estavam confusos e não sabiam por onde começar.

Nas aulas que seguiram, mais 4 horas aula, como os grupos ainda estavam com muitas dúvidas, um aluno da equipe $\mathrm{C}$ se propôs a ir ao quadro e tentar junto com os demais buscar uma pré-solução para o problema. O aluno M. apresentou no quadro, que uma das formas de fazer o trabalho, era fazer uma subdivisão da área maior e tentar encontrar por meio de interpolação polinomial, conteúdo estudado em cálculo numérico, polinômios que descrevessem o contorno da ilha e assim pudessem por meio de integral, encontrar pequenas áreas, que depois seriam somadas. E foi o que eles fizeram, como apresenta a (Fig 3.) abaixo:

FIGURA 3: Aluno da equipe C apresentando solução do problema

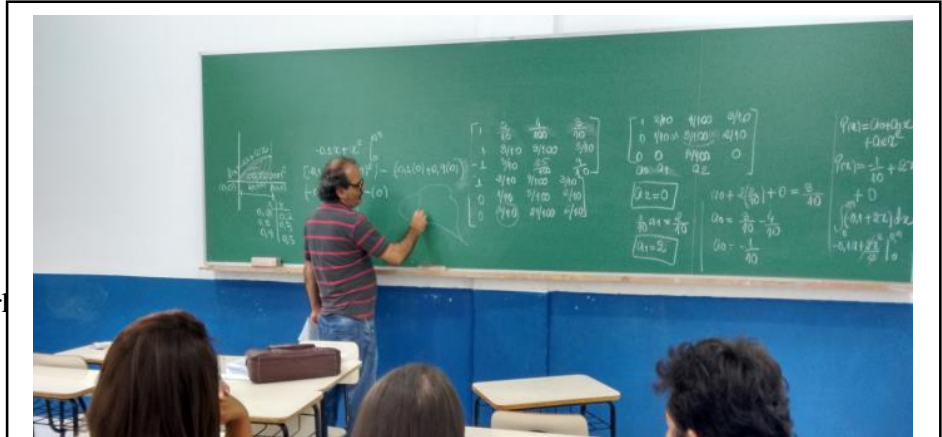


Esse encontro foi produtivo, pois os alunos conseguiram levantar algumas informações que foram relevantes para dar continuidade ao trabalho.

Para Polya (2006, p.5):

O estudante deve considerar as partes principais do problema, atenta e repetidamente, sob vários pontos de vista. Se houver uma figura relacionada ao problema, deverá traçar uma figura e nela indicar a incógnita e os dados. (POLYA, 2006, p.5)

Percebe-se que foram levantadas as partes principais do problema, usando aspectos da geometria e da álgebra. Traçaram a figura e criaram estratégias de solução.

Depois dessa aula, os alunos iriam apresentar como estavam realizando o trabalho, no entanto devido a problemas, a faculdade teve suas atividades paralisadas e o ano foi encerrado. A partir da paralisação, as comunicações foram feitas através de e-mails e mensagens via telefone.

\section{Resultados e discussões}


Os alunos deveriam resolver a proposição usando os passos da resolução de problemas propostos por Polya (2006), que são : compreensão do problema, estabelecimento de um plano, execução do plano e retrospecto. Para isso deveriam fazer um relatório escrito, contendo todos os quatro passos e como eles foram realizados.

Com relação a primeira etapa, que era a compreensão do problema, percebeu-se pelos relatos dos três grupos que conseguiram entender o solicitado. Por isso é importante que o professor apresente um problema que seja significativo para o aluno.

Os conteúdos devem ser significativos para os estudantes, isto é, precisam estar relacionados às experiências pessoais dos estudantes. Há professores que selecionam conteúdos retirados de textos elaborados em realidades muito diferentes das que são vivenciadas pelo grupo (...) (GIL, 2015, P.129)

Quando se pensa em ensino de terceiro grau, imagina-se que os alunos estão preparados para entender e assimilar quaisquer conteúdos ou conhecimentos, no entanto isso não é real.

Com relação ao segundo passo, que era a elaboração de um plano, abaixo é apresentado o relato de um dos grupos.

Quadro 1: Relato do grupo A na etapa II

ETAPA II - ELABORAÇÃO DE UM PLANO

Nunca haviamos resolvido um problema parecido com esse antes, sabíamos que havia uma escala proporcional ao tamanho real de algo, nos mapas, mas nunca 
Já o grupo C apresentou, além da primeira forma de resolução, em que utilizou o software geogebra, também utilizou uma segunda forma de resolução do problema.

Quadro 2: Relato do grupo C na etapa II

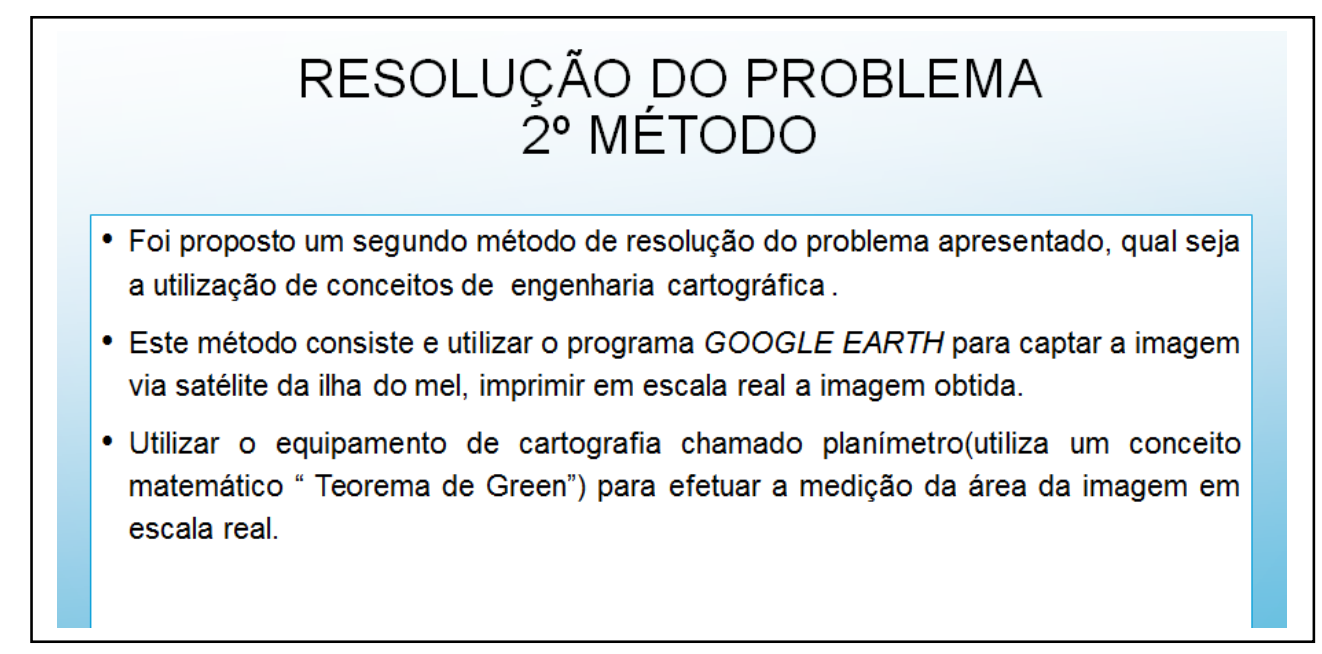

Fonte: Trabalho dos alunos (2016)

Nessa etapa o grupo C, buscou outros recursos computacionais que não foram apenas o programa Visual Cálculo Numérico, que já havia sido 
utilizado em outras aulas. Foram usados aqui, recursos da internet e o equipamento de cartografia.

$\mathrm{Na}$ terceira etapa, que consistia a execução do plano, a equipe A, apresentou que:

Quadro 3: Relato do grupo A na etapa III

\section{ETAPA III - EXECUÇĀOO DO PLANO}

Utilizaremos todos os conceitos cilados acima, inclusive o sottware.

Primeiro verificamos a fonte do mapa com escala, o cutro nào foi utilizado, para a partir do mapa criginal, poder tirar as medidas corretas em centimetros (no Paint, programa de computador). fazendo algo parecido com um gríco cartesiano. utilizando apenas a parte da Estạ̧äo Ecológiea como na figura ababxo:

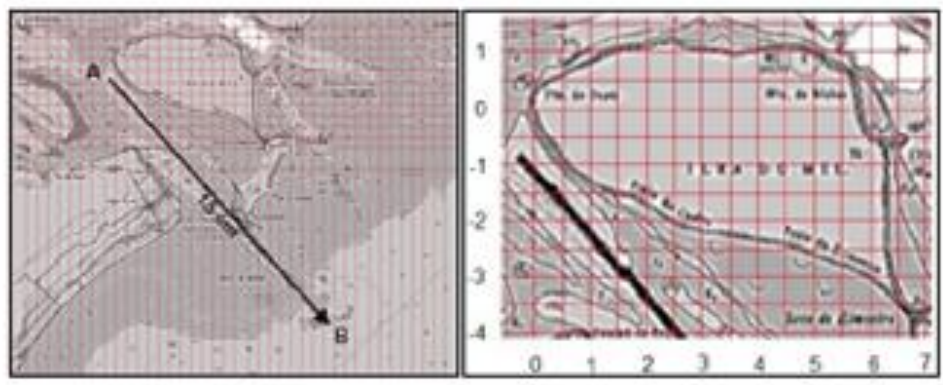

Em seguida, dividimos o mapa em 3 partes encontrando as coordenadas de cada ponto que forma cada uma das curvas. Para verificar qual o tipo de funçăo que mais se ajustaria a combinapia de pontos encontrados utizamos o item Ajuste de Curvas $\rightarrow$ Q.3 Ajuste Polinomial do software VCN, fazendo uma subdivis5o do mapa.

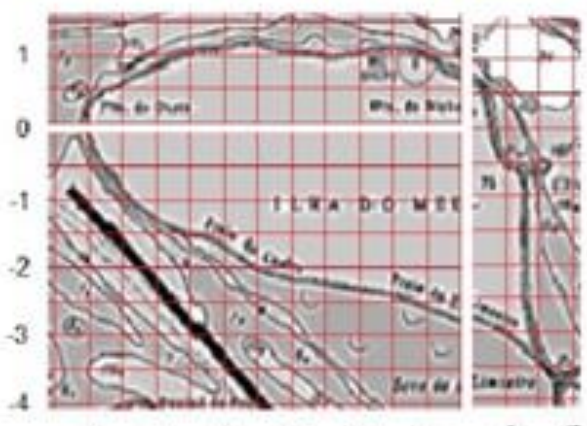

Fonte: Trabalho dos alunos alunos (2016)

\section{Quadro 4: Relato do grupo A na etapa III - Cálculos}

$1^{2}$ Subdivisão.
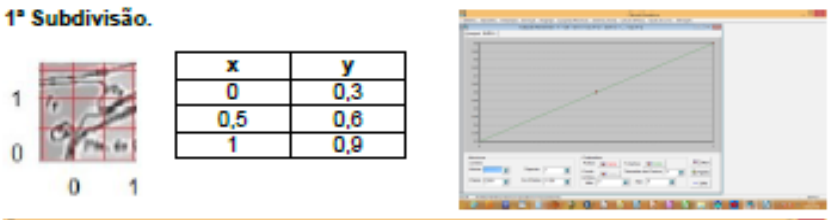
Nessa etapa, o grupo apresentou não somente a resposta, mas o erro, que nesse caso não é oriundo do levantamento de dados e nem dos cálculos, mas sim um erro do próprio equipamento que já vem especificado com o produto.

É interessante que esse tipo de erro não é tratado nas referências do Cálculo Numérico, que muitas vezes tratam apenas dos erros na fase de modelagem e de resolução que compreenderam a conversão de base, arredondamento e truncamento. Na quarta etapa, que foi o retrospecto ou verificação, foi apresentado:

Quadro 6: Relato do grupo A na etapa IV

$$
\text { ETAPA IV - RETROSPECTO OU VERIFICAÇÄO }
$$

Como a escala está em 1:100000 cm, logo, percebemos através de uma regra de très simples que $1 \mathrm{~cm}$ no mapa, equivale a $1 \mathrm{~km}$ real, pois $100000 \mathrm{~cm}=1 \mathrm{~km}$. Portanto a área é de $\frac{17901}{960} \mathrm{~km}^{2}$ que equivale a $1864,6875 \mathrm{ha}$, pois $1 \mathrm{~km}^{2}=100 \mathrm{ha}$. 
Nessa etapa, o grupo A tratou do erro absoluto e relativo, comparando a solução encontrada com a solução apresentada do problema nos guias turísticos que apresentam dados sobre a Ilha do Mel. Entre estes dados é possível encontrar os números relativos com relação à área territorial da Ilha.

Quadro 5: Relato do grupo C na etapa IV

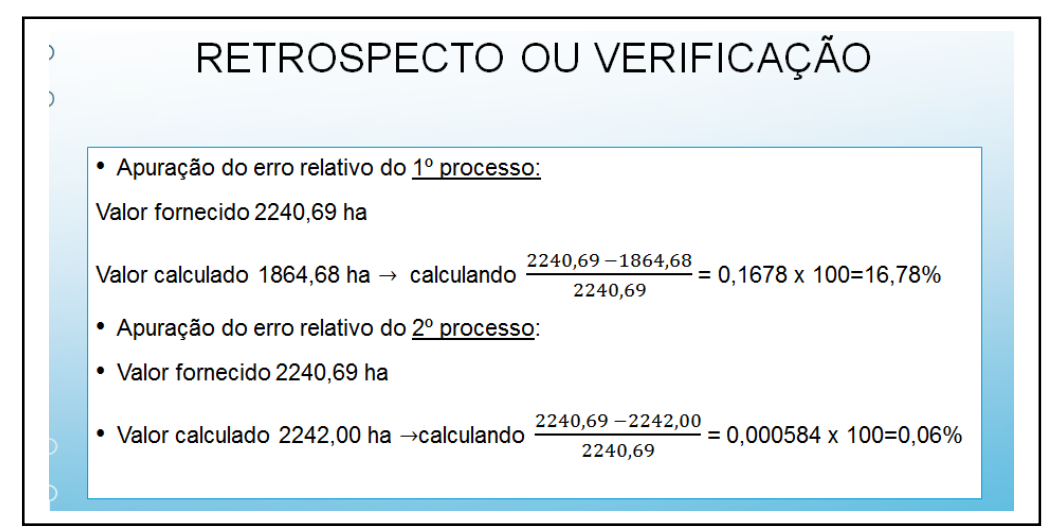

Fonte: Trabalho dos alunos (2016)

Nessa quarta etapa, pode-se perceber que os alunos utilizaram os dados reais do problema e os compararam com os valores encontrados, dessa forma, também trabalharama com o erro, que foi um dos primeiro tópicos apresentado na disciplina de cálculo numérico, ou seja, os grupos mobilizaram conhecimentos do primeiro bimestre.

Quadro 6: Relato do grupo C sobre os erros

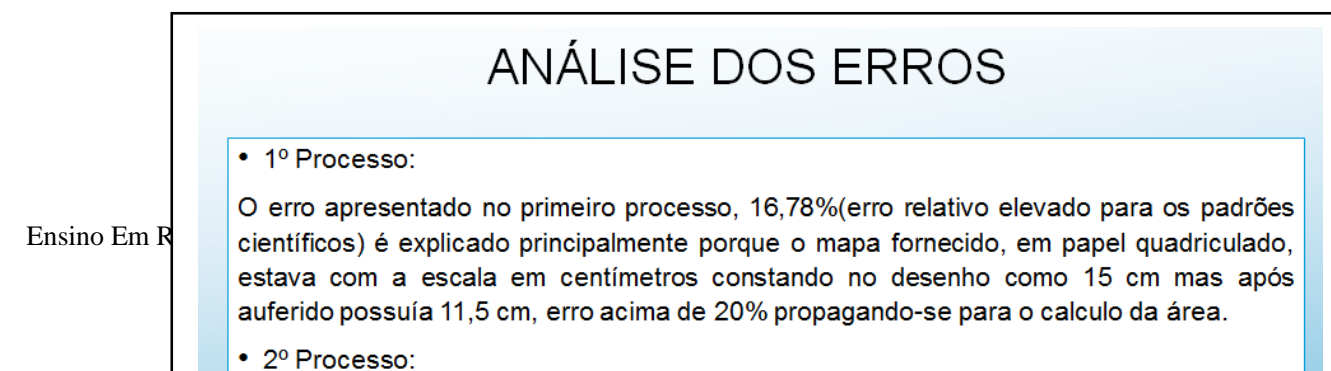


O grupo $\mathrm{C}$ fez nessa etapa um comparativo entre os dois valores encontrados por métodos diferentes, o que foi interessante, porque na apresentação foi comentado que a diferença entre os erros de $20 \%$ e de 0,06\% não foi devido aos cálculos matemáticos, mas sim à precisão do material inicial que serviu de base para inícios do trabalhos.

\section{A percepção dos alunos com relação ao trabalho}

Para que houvesse uma avaliação com relação a percepção dos alunos com relação as metodologias diferenciadas que foram desenvolvidas durante o terceiro bimestre, foi elaborado e aplicado um questionário para verificar qual a percepção deles da disciplina, as aulas teóricas e a prática realizada.

Abaixo são apresentadas as respostas dadas pelos alunos ao questionário realizado na última semanda de fevereiro de 2016. Os envolvidos responderam ao questionário impresso que depois foi transpassado para o docs do google.

Os alunos foram questionados sobre a comparação entre os trabalhos do primeiro e do segundo bimestres, comparados com o terceiro. Nas respostas $87,5 \%$ apresentaram que comparando as aulas tradicionais com a as aulas que envolveram as diferentes metodologias, eles aprenderam de 
forma diferenciada. Somente $12,5 \%$ respondeu que aprendeu mais no terceiro bimestre.

O questionário também era composto de questões abertas, que solicitavam que fossem citados pontos positivos, com relação ao trabalho com metodologias diferenciadas. As respostas foram: "Aprendizagem diferenciada", "Interação com o grupo, relação da matéria com a prática e encontros para a solução e desenvolvimento", "Estimula o raciocínio", "Consegui entender o conteúdo, mas não aplicar na prática", "Por ter sido em grupo o que facilitou a resolução de problemas" e “ 1)Resolução de problemas como método de ensino e aprendizagem de matemática, em qualquer nível. 2) Enfoque multidisciplinar na resolução de problemas".

Pelas respostas é possível perceber que os alunos se sentiram confortáveis em trabalhar em grupo, o que para eles se tornou um ponto positivo na hora de resolver problemas, além do enfoque multidisciplinar.

$\mathrm{Na}$ questão que pedia sobre as maiores dificuldades encontradas no trabalho realizado no terceiro bimestre, as respostas foram: "Encontrar a função", "Travei na função", "Encontrar a função ou polinômio interpolador e encontrar o erro", "Dificuldade em entender o que pedia", "Concentração", "Encontrar o modelo matemática para resolver o trabalho" "Entender num primeiro momento o que o trabalho estava propondo", "foi o tempo disponível para execução do trabalho, pois para quem estuda à noite é importante que a atividade seja inteiramente executada em sala de aula, nem sempre isso foi possível”.

Pelas respostas dos alunos, percebe-se que alguns conseguiram sair da fase inicial, que era entender o problema, porém não conseguiam identificar ou modelar a função.

Para outro aluno, o problema foi o tempo, como já citado anteriormente, todas as atividades estavam programadas para serem realizadas nas aulas, mas devido a paralisação, isso não foi possível e muitos tiverem que trabalhar sozinhos. 
Quanto aos pontos negativos, apenas quatro alunos responderam, e foram os seguintes comentários: "Muito pouca hora", "Aplicação prática, desenvolvimento pessoal, superar limites, interações", "os cálculos" e "não houve". Pelas respostas os pontos negativos foram variados, mas se referem ao limitado tempo para a realização da atividade, cálculos e interação entre o grupo.

A última questão tinha como objetivo identificar, entre as metodologias vivenciadas ou não pelos alunos, a qual eles adotariam quando fossem professores. Dessa forma, foi perguntado se eles fossem professores na disciplina de Cálculo Numérico, como iria trabalhar.

As respostas foram unânimes, ou seja, 100\% dos alunos apresentaram que iriam intercalar as metodologias diferenciadas com a tradicional.

Ao final do trabalho, pode-se perceber que é possível nas aulas do curso de Licenciatura em Matemática trabalhar utilizando diferentes metodologias. Alguns alunos apresentaram na pesquisa que a metodologia tradicional é onde a aprendizagem ocorre realmente, no entanto pode-se perceber pelo padrão de respostas que eles também acharam interessante as metodologias diferenciadas.

\section{Considerações finais}

Muitas vezes, ao lecionar no ensino superior, o professor pode ficar preso a metodologias tradicionais de ensino, acreditando que os alunos por estarem em um grau mais avançado de ensino não necessitem vivenciar formas de aprendizado diferentes.

No entanto, acredita-se que isso não é o ideal, sobretudo para os alunos das Licenciaturas, pois esses, provavelmente após concluírem o curso, irão lecionar na educação básica onde é necessário muitas vezes inovar. No entanto, eles não terão como trabalhar de forma diferenciada se nunca vivenciaram essa experiência. 
É necessário que as aulas dos cursos de Licenciatura, e aqui em especial do Curso de Licenciatura em Matemática, leve o aluno a ter oportunidade de pensar, de criar estratégias e novas ações, que possam servir de modelo para quando estes atuarem em sala de aula.

Nesse contexto, é que se propôs este estudo objetivando mostrar como é possível trabalhar construtivamente na disciplina de Cálculo Numérico, com metodologias diferenciadas que empregam a resolução de problemas, a modelagem matemática e novas tecnologias como forma de ajudar a minimizar os problemas de aprendizagem.

Ao ser proposto um problema para a turma onde o trabalho foi aplicado, foi possível perceber que os alunos corresponderam muito bem ao que estava sendo esperado deles, ou seja, conseguiram entender o que era proposto no problema, levantar dados, encontrar uma resposta satisfatória.

Alguns pontos positivos foram identificados no decorrer do processo, entre os quais o fato, dos alunos por exemplo, trabalharem com a questão do erro. Esse foi um tema abordado no primeiro bimestre, não esperava que fossem mobilizados tais conhecimentos, afinal a questão era para apenas encontrar a área de uma determinada região territorial.

O que ficou marcante no decorrer do trabalho, foi a busca por conceitos de outras disciplinas, como do Cálculo Diferencial Integral, da Álgebra, da Geometria e da Engenharia Cartográfica.

Por tais motivos, acredita-se que o objetivo tenha sido cumprido, pois além de vivenciar a experiência de utilizar diferentes métodos na resolução de problemas, pode-se perceber, nas respostas dadas, que se fossem professores da disciplina também iriam alternar diferentes métodos de ensino, ou seja, eles acreditam que tal procedimento pode facilitar a aprendizagem do aluno.

\section{Referências}

ALMEIDA, L.W de. Modelagem Matemática na educação básica. São Paulo: Contexto, 2013. 
ALMEIDA, L. M. W. de.; VERTUAN, R. E. Discussões sobre "como fazer" modelagem matemática em sala de aula. In: ALMEIDA, L. M. W. (Org.). Práticas de modelagem matemática: relatos de experiências e propostas pedagógicas. Londrina: Eduel, 2011.

AMARAL, T. R, et al. O ensino de cálculo numérico utilizando o scilab. Rio Grande do Sul, 2013. 9 f. Trabalho apresentado no VI Congresso Internacional de Ensino da Matemática. Ulbra, 2013.

BASSANEZI, R. C. Ensino-aprendizagem com modelagem matemática: uma nova estratégia. São Paulo: Contexto, 2002.

BRASIL. Orientações Curriculares para o ensino médio: Ciências da Natureza, Matemática e suas Tecnologias. Ministério da Educação, Secretaria de Educação Basica, 135p., 2008.

COLOMBO, J. A.; LAGOs, M. B(Org.). Problemas, Quem não tem?. Pato Branco, Imprepel, 2005.

DANTE, L.R. Didática da resolução de problemas. São Paulo: Ática, 1989.

EVES, H. Introdução a história da matemática. Campinas, SP: Editora da UNICAMP, 2004.

GIL, A. C. Didática do ensino superior. São Paulo: Atlas, 2015

HOHENWARTER, M. (2014). $O$ que é GeoGebra. 2007. Disponível em: http://www.nre.seed.pr.gov.br/cascavel/arquivos/File/CRTE/geogebra/apostila curso .pdf Acesso em: 21 de out. 2015.

NOGUTI, F. C. H. (2005). O livro “THÉORIE DES APPROXIMATIONS NUMÉRIQUES ET DU CALCUL ABRÉGÉ” de Agliberto Xavier. Dissertação (Mestrado em Educação Matemática) - Universidade Estadual Paulista, Rio Claro, 2005.

OLIVEIRA, C.C; MARIM, V. (Org.). Educação matemática: contextos e práticas docentes. Campinas, SP: Editora Alínea, 2010.

PARANAGUÁ. Guia Turístico da Ilha do Mel. Disponível em: http://www.paranagua.pr.gov.br/conteudo/guia-turistico/ilha-do-mel. Acesso $21 \mathrm{de}$ ago. 2016.

POLYA, G. A arte de resolver problemas. Rio de Janeiro: Interciência, 2006.

SPERANDIO, D. Cálculo numérico: características matemáticas e computacionais dos métodos numéricos. São Paulo: Prentice Hall, 2003. 
DOI http://dx.doi.org/10.14393ER-v25n1a2018-11

Recebido em dezembro de 2016.

Aprovado em outubro de 2017. 